\title{
Case study: How digital asset management supports account management, creative services and workflows at Ogilvy
}

\author{
Duncan Stokes \\ has spent some 30 years in the advertising, direct marketing and printing industries. For many years he was Creative \\ Services Director at the top agencies, WWAV Rapp Collins and Grey Integrated. He joined OgilvyOne nine years ago as \\ Creative Services Director. Four years ago, he took over the additional responsibility of production within Ogilvy \& \\ Mather London as Creative Services Director for both the United Kingdom and Europe regions. He is currently \\ responsible for a 75-strong production and creative services team and sits on both the OgilvyOne and O\&M Executive \\ Boards. He has spoken about digital asset management (DAM) at several leading tradeshows and conferences in 2004 \\ and 2005.
}

\section{lain Seers}

has spent some 20 years in the advertising industry. He started his working career as a finished artist in the days before Apple Computer changed the whole artwork production process. After this event, he fully embraced the new digital age of advertising by devising workflows and procedures for some of the biggest agencies in London, among them Saatchi \& Saatchi, McCann Erickson and BBDO. Now he is a Director of Creative Systems at Ogilvy \& Mather London, where he puts all of this experience to its best use. He has spoken about digital asset management and the return on investment of DAM at several leading tradeshows and conferences recently and has been widely quoted in top trade magazines on these subjects.

Keywords: digital asset management, advertising agency, return on investment (ROI)

Abstract As the advertising industry undergoes major changes and clients become more scrupulous in looking for proof that their advertising spending is paying off, agencies must search for new ways to remain competitive. Ogilvy \& Mather Ltd. London has sought to keep its edge over other agencies by building a global digital asset management system with Xinet's WebNative. The agency uses this system to deploy digital assets to 29 European Ogilvy offices and top clients in 106 countries, as well as $400+$ employees in the London hub office involved in production, account management, creative, studio, traffic department, art buying, suppliers and outside printing. The bottom line: Ogilvy's DAM system has given clients like Ford, IBM, BP, Dove/Unilever, Cisco and American Express speed to market, shortened sales lead time, and eliminated the hard and soft costs of burning and shipping CDs.

Duncan Stokes Ogilvy \& Mather Ltd 10 Cabot Square Canary Wharf London E14 4QB, UK Tel: +440207566 7264

Email: duncan.stokes @ogilvy.com

\section{INTRODUCTION}

Everyone knows the advertising industry is in a state of upheaval. The old ways of doing business aren't as profitable as they used to be. While agencies are trying to fit the traditional media world into the new-media world, marketers are demanding better proof that their ad spending is actually paying off. Multimillion-dollar accounts can be gained or lost with a moment's notice, often based upon a single deciding factor - which agency can get the client the most visibility worldwide for the least amount of money.

To enhance our competitive edge in 


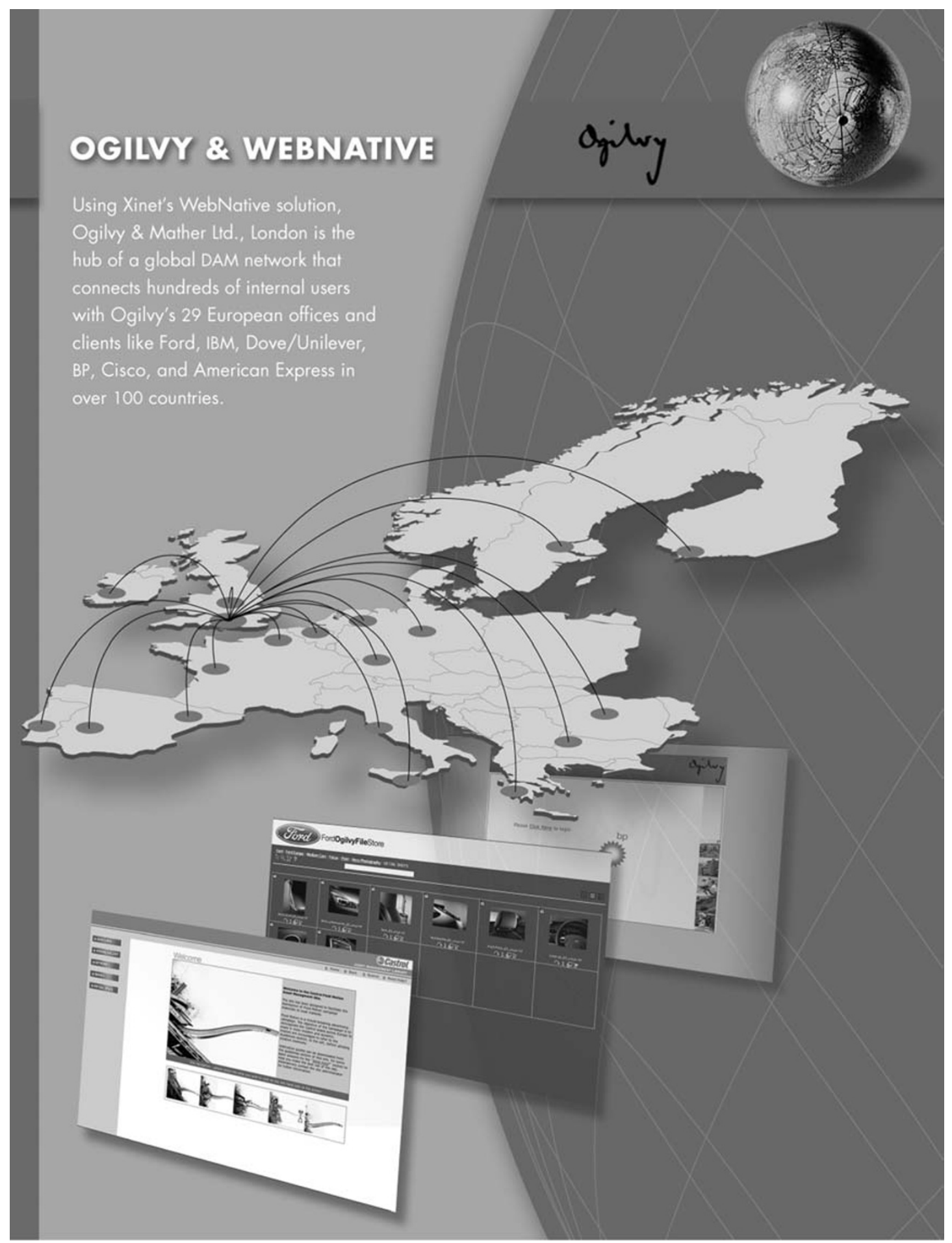

Figure 1 Ogilvy's European DAM hub 
winning accounts, Ogilvy \& Mather Ltd., an agency at the forefront of creativity and technology systems since its founding in 1948, built a digital asset management (DAM) system that connects Ogilvy London internal departments with 29 European Ogilvy offices and top clients in 106 countries (Figure 1).

With Xinet's WebNative asset management solution as our foundation, Ogilvy uses our DAM solution to set ourselves apart from the competition. Since 2001, we've used WebNative to manage and protect the brands of clients like Ford, IBM, BP, Dove/Unilever, Cisco and American Express; give these clients speed to market; shorten our sales lead time, and save money for the agency and clients by eliminating the hard and soft costs of burning and shipping CDs.

Xinet's WebNative provides webbased, 24/7 access to live and archived files (Figure 2), and image and layout- handling functionality. WebNative Venture is an integrated database that allows users to search for assets using standard or unlimited customized metadata. With the DAM solution, people can contribute to the back-end systems without leaving their common work environment, such as designers accessing low-resolution images through a web interface. The solution creates a transparent workflow by not changing the workflow already in place.

Running off Ogilvy's server at the London headquarters office, images and brands are accessed securely from any location worldwide beyond the firewall. Through a series of customized websites designed for each client and product, Ogilvy's art directors, production, account management, studio, creative, traffic department, art buyers and suppliers can access, develop and approve shots, images, brands, and layouts via the internet wherever they are in the world.

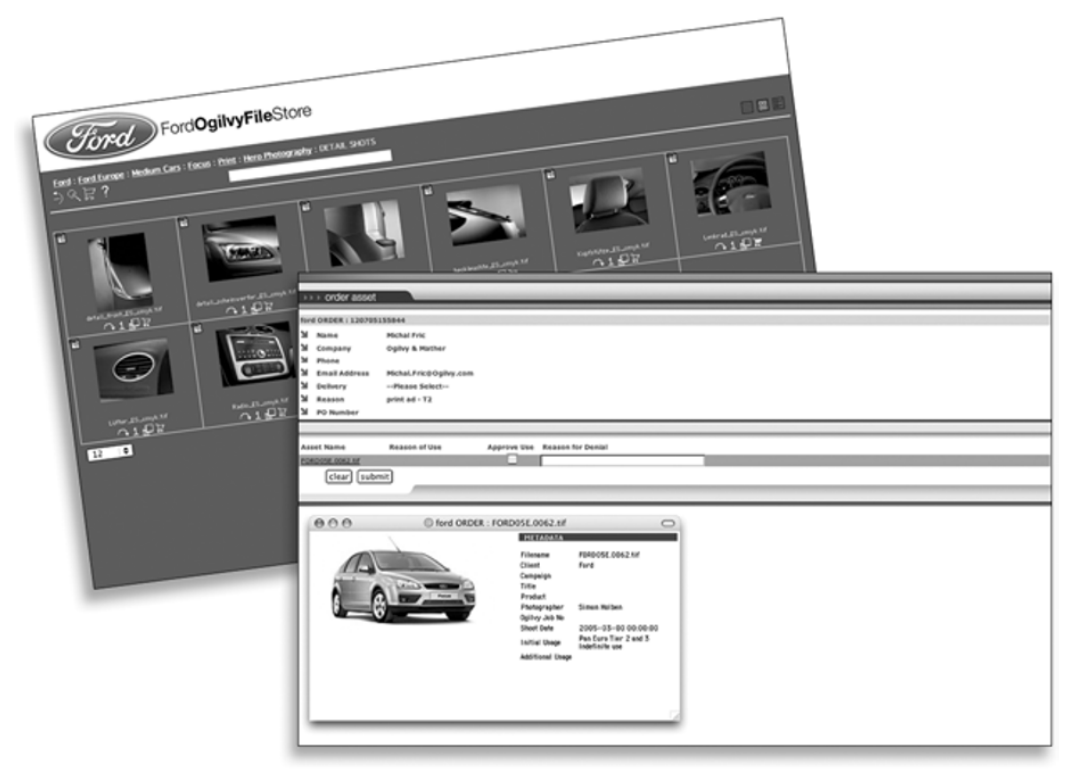

Figure 2 Ogilvy uses Xinet's WebNative DAM solution to provide its clients and partner offices with web-based, 24/7 access to live and archived files 
In a nutshell, when clients come to us because they want fulfillment across Europe or the world, we show them that we have a global DAM system already in place to provide precisely that.

\section{MOMENT OF TRUTH}

The 'moment of truth' that led to this system came four years ago when we were still using Canto's Cumulus for asset management and FTP and ISDN for file delivery. We were frustrated because Cumulus could not grow with us as our number of digital assets grew exponentially, and FTP was such a cumbersome workflow system.

After reviewing the top DAM solutions on the market, we realized that we could achieve what we needed with Xinet's WebNative. It gave us a tick for every box: it replaced FTP, had wider capabilities than Cumulus, distributed files across Europe, and could be tailored for our expanding needs.

We implemented WebNative agencywide, and you will read here about our ensuing success with it. However, to remain at the cutting edge of technology, we routinely investigate other DAM solutions on the market. If we were shopping for a digital asset management system today and doing a review of every solution available, Ogilvy would still choose WebNative because it is the best solution for our needs.

\section{WHY AND HOW OGILVY USES DAM: EVERYTHING IS DIGITAL}

Before undertaking the development and execution of an agency-wide DAM project, one must understand why the need for DAM in the advertising industry is more pressing today than ever: everything is digital.
Digital photography, now the worldwide standard for advertising imagery, puts high-resolution images higher up in the process. DAM is the ability to provide and share assets easily. At Ogilvy, we use a true digital workflow from the beginning of the process, when a photographer takes a digital photograph of a product or fashion model, to the end of the process, when the final ad is sent digitally to the magazine, newspaper, billboard, store or web page, where the public views it.

Prior to implementing Xinet's WebNative as the way to access and distribute our digital assets, we burned entire ad campaigns onto CDs and shipped them worldwide via courier to partner offices overseas and clients. Every time a campaign was updated, a new CD had to be burned and distributed to each location again to replace the old CD. There were endless multiple costs attached to this, as it involved not just one CD, but hundreds each time an asset of a campaign was modified.

With the Xinet solution, we can demonstrate to our clients the enormous savings in hard and soft costs because we have eliminated the time, labor and expense of burning CDs and paying courier fees (Figure 3).

Now Ogilvy London is the hub of the DAM operation with nearly 600 people here that can use it every day: production, account management, creative, studio, traffic department, art buying, suppliers, and outside printers. All 29 large European Ogilvy offices use the DAM solution as well.

The Xinet solution gives us a place to store our data and numerous ways to access that data to the printing environment. Yet that access is not just 


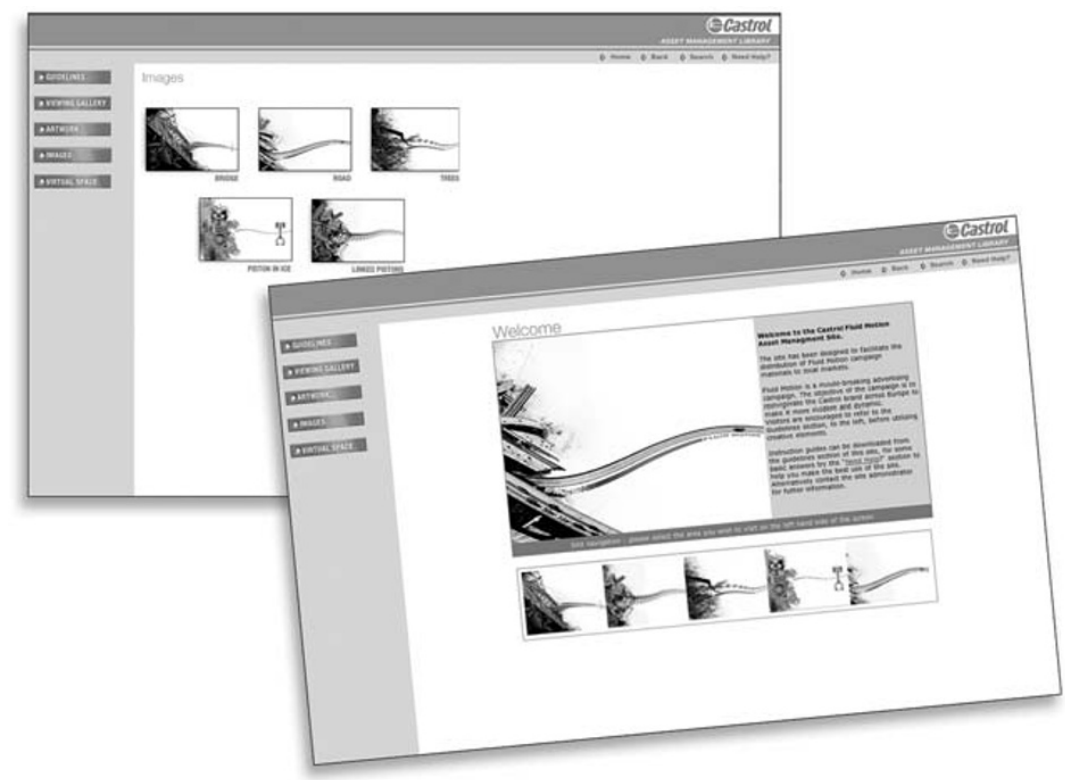

Figure 3 With the Xinet solution, Ogilvy has shown clients the enormous savings in hard and soft costs by eliminating the time, labor and expense of burning CDs and paying courier fees

limited to remote users: nearly 400 people here in London use the DAM system every day internally.

\section{HOW TO PITCH AND BRAND FOR DAM}

Each Ogilvy client gets a DAM system branded uniquely for them because every client has a different workflow and requirements.

When we pitch the DAM system to a client, we often show them how we're using it with other unnamed clients. We discuss the intricacies of how they might use it in each particular market. It helps marketers once they see how they can utilize the system to access their work during and after an ad campaign, and how they get ticks in every box because it's a tangible return on investment (ROI) for their spending.

Since WebNative is so easy to customize, it takes Ogilvy very little time to tailor a demo presentation for potential clients with their company's specific logos and images on it. Clients love seeing their logos on a demo. Once we've created a demo site, we let the client use it for a month for free to give them $24 / 7$ access to their digital assets via the internet so they can view, approve, download and re-purpose assets anytime. Within a month, the client has so many assets on the free demo site and so many hits on it that the site is indispensable to them and they clearly see the value to paying for it as a DAM service.

It is simple to create bespoke websites for each client, specific websites geared for a client's needs or the unique tasks of a particular ad campaign. WebNative's easy customization makes the turnaround time for building these individual bespoke websites for clients straightforward

\section{SPEED TO MARKET, REDUCED COSTS}

The WebNative DAM system gives our clients more control and increased speed 
to market which helps us do our work cheaper and faster. This stems from empowering clients with the ability to access their imagery anytime from any web browser in the world.

For example, before our DAM system was in place, the local market office of a client would ring up the main office to say they wanted a particular picture of a product bottle. Once you shipped them the CD containing the image, they'd say "No, that's not the one I want." Now the client can go online into their customized DAM site to search and download the exact product bottle image themselves.

This gives our clients speed to market in four critical ways:

- an advertising campaign can go live one or two days earlier because you don't need to wait for their CD to arrive via courier;

- it empowers local markets to choose the images they need for their specific local markets;

- they don't have to wait to download a whole file from an FTP site or reshoot an image;

- state-of-the-art file compression technology, co-developed by us, is used to deliver large image files to "low bandwidth" markets.

Even more client costs are reduced by the sharing of images across different Ogilvy divisions, such as advertising, direct marketing, etc. As clients become more scrupulous in looking at new ways to reduce advertising costs, we can offer suggestions on how they can be more efficient, which makes them feel innovative and in control of how their advertising budget is being spent.

\section{DAM HELPS RETAIN CLIENTS, GIVES INCREASED SECURITY}

Embracing DAM has certainly helped

Ogilvy retain accounts because agencies today must show clients we are exploring new ways to reduce costs for them. With DAM, we can show them the tangible hard and soft cost savings from no longer having to burn the CD and pay for couriers.

For example, it is easy to show clients the time, labor and expense costs of cutting five CDs of images and shipping them to different markets. Put an hourly rate on all those tasks, both for the head office and the partner offices that receive the CDs, then tally all those up and you've got quite a big number.

Perhaps what clients like best about the DAM system is that it gives them more security over their branding. Clients are increasingly concerned about where their images appear and fraudulent uses of their branding. Xinet's WebNative DAM system gives clients more control over fraudulent use of packaging because the user environment is solely accessed through a secure website with user name and password protection.

\section{CREATIVES LOVE VISUALS: EVERYONE'S HAPPY}

What guaranteed our success with WebNative is the solution's usability. WebNative is very intuitive and visual, which helped with user adoption agency-wide. Creatives love it because they can get to a thumbnail preview image immediately.

We've never had a single customer complaint with our DAM system. We do a basic user guide and send it to clients. Then they just jump on the system and figure it out because it's so 
intuitive. Part of how we engage with the client is to organize the DAM system according to the method that they are already operating. We organize the file structure the way they normally reference their assets. The beauty of WebNative is that it doesn't force you to change the way you do business. It's simply a transparent workflow that enhances the way you work.

From an internal agency perspective, this DAM system makes our job more interesting and more fun, as there is nothing interesting about burning and couriering CDs all day. Our staff feel more fulfilled because they can actually see revenue that they're generating. The new revenue is easy to see since the ROI on the software itself was paid off within three months. When you factor in hardware costs, it was covered within a year. 